\title{
Changes in long jump take-off technique with increasing run-up speed
}

\author{
LISA A. BRIDGETT ${ }^{1} \&$ NICHOLAS P. LINTHORNE ${ }^{2}$ \\ ${ }^{1}$ School of Exercise and Sport Science, The University of Sydney, PO Box 170, Lidcombe, NSW 1825, Australia \\ ${ }^{2}$ School of Sport and Education, Brunel University, Uxbridge, Middlesex, UB8 3PH, United Kingdom
}

\begin{abstract}
The aim of the study was to determine the influence of run-up speed on take-off technique in the long jump. Seventy-one jumps by an elite male long jumper were recorded in the sagittal plane by a high-speed video camera. A wide range of run-up speeds was obtained using direct intervention to set the length of the athlete's run-up. As the athlete's run-up speed increased the jump distance and take-off speed increased, the leg angle at touchdown remained almost unchanged, and the take-off angle and take-off duration steadily decreased. The predictions of two previously published mathematical models of the long jump take-off are in reasonable agreement with the experimental data.
\end{abstract}

Keywords: athletics, take-off angle, long jump, sports biomechanics.

\section{Introduction}

Long jumping performance is determined primarily by the athlete's ability to attain a fast horizontal speed at the end of the approach run. To make best use of the run-up speed the athlete must use an appropriate take-off technique to launch the body into the air. Alexander (1990) developed a simple mathematical model of jumping that explained the principles that govern the optimum take-off technique in the long jump. The model was later refined by Seyfarth, Blickhan and Van Leeuwen (2000), and both studies concluded that in addition to a fast run-up the athlete must plant the take-off leg at about $65^{\circ}$ to the horizontal.

Alexander (1990) and Hay (1993a) explain the optimum take-off technique by noting that the athlete requires a large horizontal speed at take-off to travel forward, and a large vertical speed to give time in the air before landing back on the ground. A fast run-up produces a large horizontal takeoff speed, but it also shortens the duration of the ground contact and hence the ability of the athlete to generate a vertical impulse (force integrated over time). To increase the duration of the foot contact the athlete plants the foot ahead of the centre of mass at touchdown. However, the resulting increase in vertical propulsive impulse is accompanied by an undesirable increase in horizontal braking impulse. Therefore, there is an optimum leg angle at touchdown which offers the best compromise between generating a vertical propulsive impulse and generating a horizontal braking impulse.

The jump simulations by Alexander (1990) and Seyfarth et al. (2000) indicate that the optimum take-off technique changes as the run-up speed is increased. The purpose of the present study was to obtain experimental data for the relations between run-up speed and take-off technique for an experienced male long jumper, and to compare the data with the predictions of Alexander (1990) and Seyfarth et al. (2000).

\section{Methods}

Results from mathematical models of the long jump take-off

In Alexander's simple model of jumping, the athlete's takeoff leg is considered as a chain of two rigid segments (thigh and shank) of the same length $(50 \mathrm{~cm})$. The leg segments have zero mass and the entire mass of the athlete is represented by a point mass at the hip. A single torque generator at the knee represents the combined contributions of the knee, hip and ankle extensor muscles. This torque generator is fully activated while the leg is in contact with the ground, and the knee extensor muscles have a constant moment arm at the knee joint. The movements of the knee are accompanied by changes in the length of the contractile and series elastic components of the knee extensor muscles, and the knee torque decreases with increasing joint angular velocity according a version of Hill's (1938) equation.

In Alexander's model, the technique variables that the athlete may select are those that describe the state of the athlete at the instant of touchdown. These variables are the horizontal speed and vertical speed of the centre of mass, the angle of the take-off leg to the horizontal, and the angle of the knee of the take-off leg. In Alexander's simulations, only the horizontal speed at touchdown and the leg angle at touchdown were systematically varied. He fixed the vertical speed at touchdown at $0 \mathrm{~m} \cdot \mathrm{s}^{-1}$, which is in approximate agreement with experimental data from athletes, and the knee angle at touchdown was fixed at $170^{\circ}$ (rather than $180^{\circ}$ ) so as to avoid generating an infinite ground reaction force at touchdown. The model of the take-off therefore operated on two input technique variables (run-up speed and leg angle at touchdown) to produce values for the output jump parameters (jump distance, take-off angle, take-off duration and ground reaction force profile).

Alexander's investigation concentrated on the influence of run-up speed and leg angle at touchdown on the jump distance. The simulated jump distances and optimum take- 
off technique were in reasonable agreement with observations of actual athletes, and the ground reaction force profile had a moderately realistic shape in that the vertical force exhibited a high initial peak followed by a plateau. A sensitivity analysis showed that the jump distance and optimum take-off technique were not strongly influenced by the muscle compliance or by the maximum shortening speed of the muscle.

Seyfarth et al. (2000) modified Alexander's model by introducing a more detailed representation of the musculotendon unit. In their model, the series and parallel elastic components were characterized by a non-linear stress-strain relationship, and their investigation concentrated on the influence of the properties of the muscle and tendon on the jump distance and optimum take-off technique. Seyfarth et al. decided to use longer leg segments $(60 \mathrm{~cm})$ than Alexander, arguing that the leg pivots about the ball of the foot, rather than the heel, and that a model should account for the plantar flexion of the foot at touchdown and take-off.

The results obtained by Seyfarth et al. were similar to those of Alexander. The optimum take-off technique was to run-up as fast as possible and the athlete must plant the takeoff leg at about $65^{\circ}$ to the horizontal. Jumping performance was insensitive to tendon compliance and muscle speed, but greatly influenced by muscle strength and by the value of the maximum eccentric force in relation to the maximum isometric force. The optimum leg angle at touchdown was insensitive to run-up speed and to the properties of the muscle and tendon. Seyfarth et al. also noted that the athlete had a net loss of mechanical energy during the takeoff phase.

The present study compares the predictions of Alexander (1990) and Seyfarth et al. (2000) with experimental data from an experienced male long jumper. Alexander and Seyfarth et al. reported their simulation results as contour plots of the output jump parameters (e.g. jump distance, take-off angle, mechanical energy) as a function of the two input technique variables (run-up speed and leg angle at touchdown). These contour plots present an effective overview of how the combinations of technique variables affect the jump parameters. However, the present study is concerned with how the optimum values of the technique variables and jump parameters vary with run-up speed. As the run-up speed in the simulated jumps increases, the optimum value of a technique variable or jump parameter traces a continuous curve on the contour plots, and these optimum values were read directly from the graph. All results used in the present study were as reported in the original studies. The models of Alexander and Seyfarth et al. were not reconstructed, and the simulations were not reproduced.

\section{Measurements of the long jump take-off}

Experimental data for the relations between run-up speed and take-off technique were obtained using a single-subject technique intervention study (Greig \& Yeadon, 2000). An experienced male long-jumper with a personal best long jump performance of $8.30 \mathrm{~m}$ was recruited and asked to perform jumps using a wide range of run-up speeds. The study was approved by the Human Ethics Committee of the
University of Sydney, the participant was informed of the protocol and procedures prior to his involvement, and written consent to participate was obtained.

The athlete was recorded at four competition and nine training sessions. All jumps were performed with maximum effort, and the athlete jumped in regular long jump pits that had a synthetic all-weather runway and a standard wooden take-off board. In the competition sessions and in some training sessions, no direct intervention was used and the athlete jumped using his usual run-up length (18 or 20 strides) and run-up speed (10.0-11.1 $\left.\mathrm{m} \cdot \mathrm{s}^{-1}\right)$. Two intervention sessions were used in which the run-up speed was reduced by shortening the length of the run-up to 14 , 12, 6 or 2 strides. The athlete was highly experienced and regularly performed maximum-effort jumps from a short run-up as part of his normal training program. We therefore assumed that at all run-up speeds his take-off technique would be very close to his optimum technique for that runup speed.

A JVC GR-DVL9800 high-speed video camera operating at $100 \mathrm{~Hz}$ was used to record the jumps. The camera was placed between 15 and $25 \mathrm{~m}$ from the middle of the long jump runway, with the optical axis of the camera perpendicular to the long jump runway and in line with the front edge of the take-off board. The field of view of the camera was zoomed so that the athlete was visible from the first contact of the last stride before take-off, through to about $4 \mathrm{~m}$ after take-off. The movement space was calibrated with two $2.10 \mathrm{~m}$ high poles that were placed along the midline of the runway and from 3.0 to $5.2 \mathrm{~m}$ apart, depending on the available space at the venue. A fibreglass tape was used to measure the jump distance, which is the perpendicular distance from the take-off line to the break in the landing area nearest to the take-off line (IAAF, 2004). The wind velocity was measured on all competition jumps, and performances in which the wind velocity was not between -2 and $+2 \mathrm{~m} \cdot \mathrm{s}^{-1}$ were excluded from the analysis.

An Ariel Performance Analysis System was used to analyse the video images of the jumps. Eighteen body landmarks that defined a 16-segment model of the athlete were digitised in each image. The segmental data used were those proposed by Dempster (1955) for male adults, and the two-dimensional coordinates of the body landmarks and the athlete's centre of mass were calculated from the digitised data using the direct linear transform (DLT) algorithm. Coordinate data were smoothed using a second-order Butterworth digital filter with a cut-off frequency of $10 \mathrm{~Hz}$, and the velocity of the athlete's centre of mass was calculated from the coordinate data using the finite differences method (Winter, 1990). The choice of cut-off frequency was based on a residual analysis (Winter, 1990) and a visual inspection of the power spectra of the coordinate and velocity data.

To be consistent with the mathematical models of the take-off, the leg angle in this study was defined as the angle relative to the horizontal plane of a line joining the hip and the ankle joints of the take-off leg. Similarly, the knee angle was the angle enclosed by the lines that join the hip, knee and ankle joints of the take-off leg. The instant of touchdown was defined as the first clear frame in which the 
take-off foot was in contact with the ground, and the instant of take-off was the first clear frame in which the take-off foot was observed to break contact with the ground (Hay, Miller, \& Cantera, 1986; Lees, Graham-Smith, \& Fowler, 1994). The run-up speed of the athlete was taken as the horizontal speed of the athlete's centre of mass at the instant of touchdown, and the athlete's take-off speed and take-off angle were calculated from the horizontal and vertical speed of the athlete's centre of mass at the instant of take-off.

The total mechanical energy of the athlete was calculated as the sum of the kinetic energy and gravitational potential energy of the centre of mass of the athlete. In calculating the gravitational potential energy of the athlete the zero reference height is arbitrary, and in this study was set to ground level so as to be consistent with the choice used by Seyfarth et al. (2000). In the long jump take-off the rotational kinetic energy of the athlete about the centre of mass is relatively small $(<2 \%)$, and so was not included in the calculation of total mechanical energy (Avela, Kryolainen, Komi, 1988; Herzog, 1986).

Regression curves were fitted to the experimental data using the predicted relations from the models of Alexander (1990) and Seyfarth et al. (2000) as a guide to the form of the fitted curves. The fitted curve that produced the lowest coefficient of variation in the regression equation coefficients was taken to be the most appropriate fit to the data.

In this study, the measurement uncertainties were assumed to be similar to the uncertainties reported by Lees, Fowler and Derby (1993) for a study of the long jump takeoff that used a similar experimental method and analysis procedure. They calculated the average variation in values obtained by four different experimenters who each digitised a selection of four jumps. The estimated uncertainties were about $3 \mathrm{~cm}$ for linear displacement, $0.3 \mathrm{~m} \cdot \mathrm{s}^{-1}$ for run-up speed and take-off speed, $2^{\circ}$ for take-off angle and leg angle, and $5^{\circ}$ for knee angle. These values are consistent with the expected increase in relative uncertainty that arises from the smoothing and differentiation of position data and the calculation of joint angles from position data (Challis, 1997). In the present study, all the trials were digitised by the same person, and so the above estimates of uncertainty may be unduly pessimistic. The standard deviation in the data that arose from repeated digitising of jumps by the investigator was about $1.0 \mathrm{~cm}$ for linear displacement, 0.15 $\mathrm{m} \cdot \mathrm{s}^{-1}$ for run-up speed and take-off speed, $1.5^{\circ}$ for take-off angle, and $1.5^{\circ}$ for leg angle and knee angle. Another substantial source of uncertainty in the measured variables is the precise determination of the instants of touchdown and take-off. There could easily be an error of half a frame in determining these instants. The uncertainty due to the video sampling rate was quantified by calculating one half the difference between the value at the instant of touchdown (or take-off) and the value at one frame before the instant of touchdown (or take-off). The calculated uncertainties due to the video sampling rate were about $0.15 \mathrm{~m} \cdot \mathrm{s}^{-1}$ for run-up speed and take-off speed, $0.7^{\circ}$ for take-off angle, $2.5^{\circ}$ for leg angle, $2.0^{\circ}$ for knee angle, and $5 \mathrm{~ms}$ for take-off duration.

In this study, the run-up speed of the athlete was taken as the horizontal speed of the athlete's centre of mass at the instant of touchdown. An alternative method of estimating the run-up speed is from the average horizontal speed of the jumper's centre of mass over the flight phase of the last stride before take-off (Yu, 1996). Lees et al. (1993) reported that in their long jump study the instantaneous speed values were systematically less than the average speed values, probably because of oversmoothing of the touchdown impact. However, the difference was relatively small $\left(0.25 \mathrm{~m} \cdot \mathrm{s}^{-1}\right)$, and was within the estimated uncertainty of the run-up speed data. Therefore, the instantaneous horizontal speed of the athlete's centre of mass at the instant of touchdown may be taken as an adequate estimate of the athlete's run-up speed.

\section{Results}

Table I lists the average values of the jump variables for the performances at the athlete's competition run-up length. These values are consistent with published competition data for male long jumpers, and so the relations between the jump variables and run-up speed obtained in the present study are likely to be representative of experienced male long jumpers (Arampatzis, Brüggemann, \& Walsch, 1999; Hay et al., 1986; Lees et al., 1994; Nixdorf \& Brüggemann, 1988, 1990).

Table I. Values of jump variables for an experienced male long jumper when using his competition run-up length (mean $\pm s$; $n=$ 22).

\begin{tabular}{lc}
\hline jump distance $(\mathrm{m})$ & $7.89 \pm 0.16$ \\
run-up speed $\left(\mathrm{m} \cdot \mathrm{s}^{-1}\right)$ & $10.4 \pm 0.3$ \\
take-off speed $\left(\mathrm{m} \cdot \mathrm{s}^{-1}\right)$ & $9.6 \pm 0.4$ \\
take-off angle $\left({ }^{\circ}\right)$ & $21.2 \pm 0.4$ \\
knee angle at touchdown $\left({ }^{\circ}\right)$ & $167 \pm 4$ \\
leg touchdown at touchdown $\left(^{\circ}\right)$ & $61 \pm 3$ \\
take-off duration (ms) & $127 \pm 11$ \\
$\frac{\text { mechanical energy at take-off }}{\text { mechanical energy at touchdown }}(\%)$ & $90 \pm 5$ \\
\hline
\end{tabular}

\section{Jump distance}

As expected, the athlete jumped farther as the run-up speed increased (Figure 1). The long jump is essentially a projectile event and so an increase in take-off speed (due to an increase in run-up speed) should lead to a greater flight distance. For the jumps at his competition run-up length, the jump distance for this athlete increases at a rate of about $6 \mathrm{~cm}$ per $0.1 \mathrm{~m} \cdot \mathrm{s}^{-1}$ increase in run-up speed. Siluyanov and Maximov (1978) reported similar values from longitudinal studies of the competition performances by the former world record holders, Bob Beamon (USA) and Igor TerOvanesian (URS). 


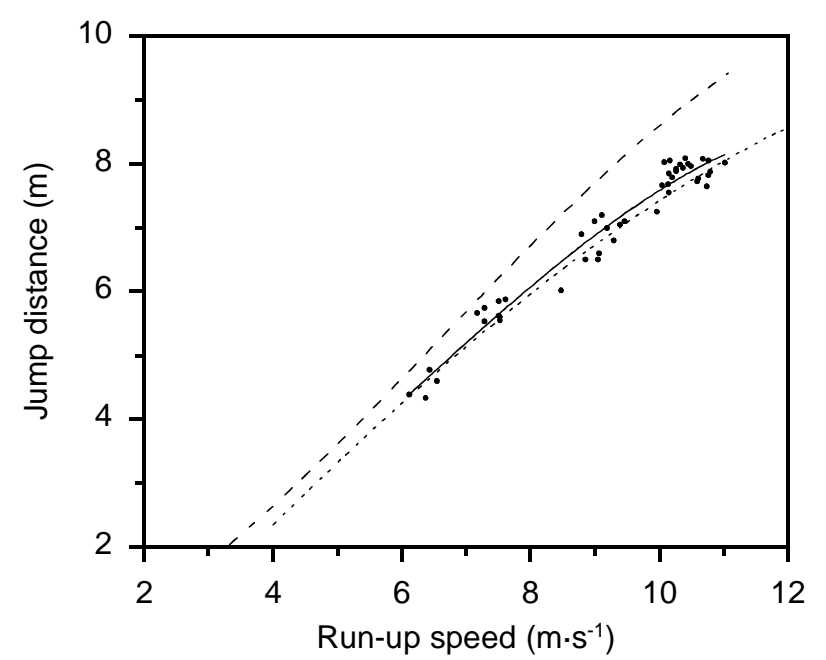

Figure 1. Increase in jump distance with increasing run-up speed for an experienced male long jumper. Also shown is a seconddegree polynomial curve of best fit to the data (solid line). The simulation results from the mathematical models of Alexander (long-dashed line) and Seyfarth et al. (short-dashed line) are in reasonable agreement with the experimental data.

The predicted relations between jump distance and runup speed from the mathematical models of Alexander (1990) and Seyfarth et al. (2000) are in reasonable agreement with the experimental data, and this suggest that the models contain the essential features of the long jump take-off (Figure 1). Jump distance was not expected to show a linear increase with increasing run-up speed. The models of Alexander and Seyfarth et al. suggest that the rate of increase in jump distance decreases slightly with increasing run-up speed, and that the relation may be expressed by a second-degree polynomial. When fitting curves to the experimental data, a second-degree polynomial produced a slightly lower coefficient of variation in the regression equation coefficients than a linear fit.

\section{Take-off speed}

The resultant take-off speed is the vector sum of the horizontal and vertical take-off speeds. Even though the jumper generated vertical speed during the take-off, the athlete was still able to transfer most of his run-up speed through to horizontal take-off speed and so the resultant take-off speed steadily increased with increasing run-up speed (Figure 2). Over the range of run-up speeds analysed here, the vertical take-off speed remained constant at about $3.4 \mathrm{~m} \cdot \mathrm{s}^{-1}$. The jumping action always resulted in a reduction in horizontal speed, and the magnitude of this speed reduction steadily increased as the run-up speed increased. Unfortunately, Alexander (1990) and Seyfarth et al. (2000) did not report simulation results for the relation between take-off speed and run-up speed.

The observed vertical take-off speed $\left(3.4 \mathrm{~m} \cdot \mathrm{s}^{-1}\right)$ is probably about $85-95 \%$ of the maximum vertical take-off speed that this athlete could achieve in a jumping movement. This assertion is based on the assumption that the athlete can produce a high jump performance similar to that of a world-class decathlete, where the centre of mass reaches a peak height of $2.0-2.2 \mathrm{~m}$. In high jumping, the height of the centre of mass at take-off height is about $73 \%$ of the athlete's standing height $(1.88 \mathrm{~m})$, and so the required vertical take-off speed is $3.5-4.0 \mathrm{~m} \cdot \mathrm{s}^{-1}$ (Dapena, McDonald, \& Cappaert, 1990).

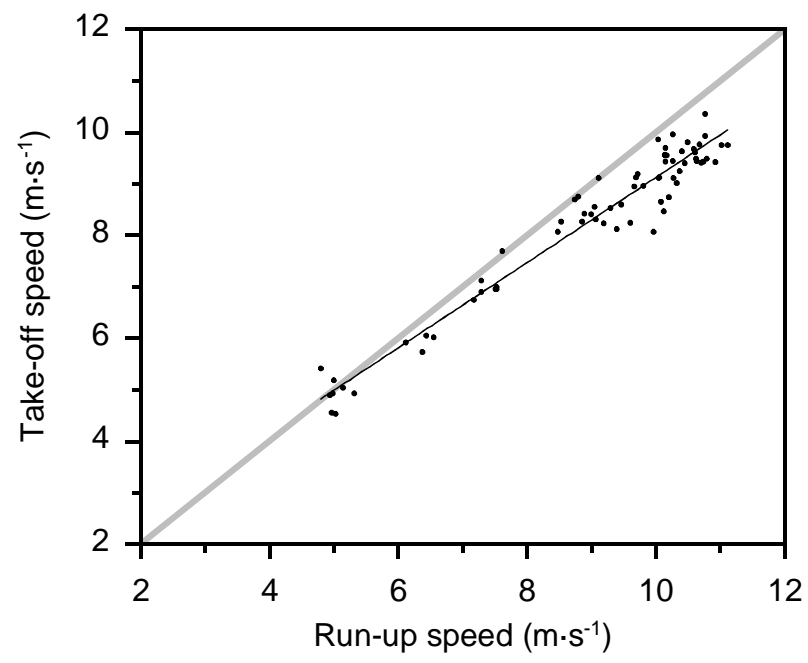

Figure 2. Increase in take-off speed with run-up speed. Also shown is the line of best fit to the data (solid line), and the line of $100 \%$ transfer of run-up speed to take-off speed (grey line). No simulation results are available for comparison.

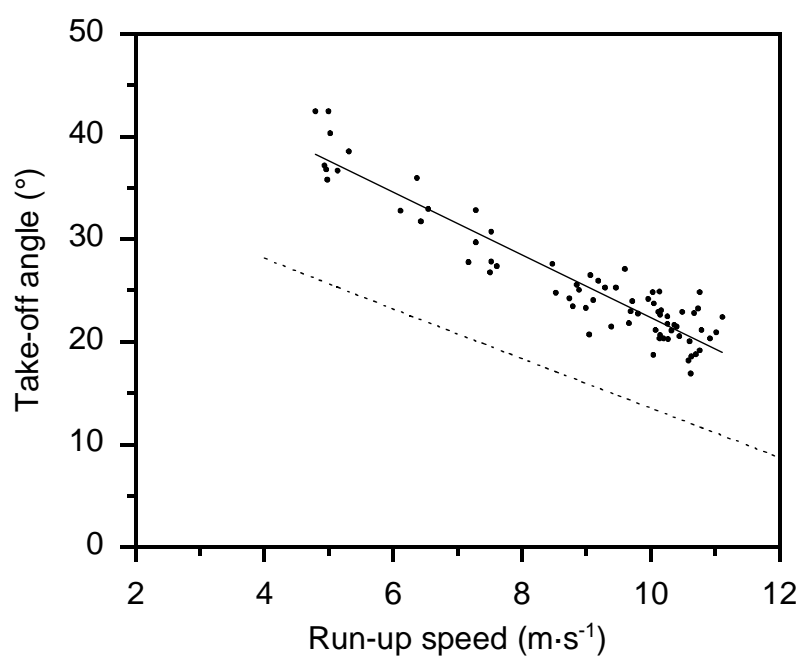

Figure 3. Decrease in take-off angle with run-up speed. Also shown is the line of best fit to the data (solid line), and the simulation results from the mathematical model of Seyfarth et al. (short-dashed line).

\section{Take-off angle}

The take-off angle is determined by the ratio of the vertical take-off speed to the horizontal take-off speed. For the athlete studied here, the optimum take-off angle steadily decreased with increasing run-up speed (Figure 3). Changes in take-off angle were determined by changes in horizontal take-off speed because the athlete's vertical take-off speed 
remained constant. As the athlete increased his run-up speed, the horizontal speed at take-off increased and so the take-off angle decreased.

The observation that the athlete used the same vertical take-off speed at all run-up speeds is consistent with the accepted biomechanical explanation of the optimum take-off angle in the long jump (Linthorne, Guzman, \& Bridgett, 2005). At run-up speeds greater than about $4 \mathrm{~m} \cdot \mathrm{s}^{-1}$ the optimum take-off angle is less than the $45^{\circ}$ value that is commonly proposed for a projectile in free flight. A takeoff angle of $45^{\circ}$ requires that the horizontal and vertical take-off speeds are equal. At run-up speeds above $4 \mathrm{~m} \cdot \mathrm{s}^{-1}$ the athlete can produce a greater horizontal take-off speed (through using a fast run-up) than the maximum possible vertical take-off speed (about $4 \mathrm{~m} \cdot \mathrm{s}^{-1}$ ), and so the athlete jumps with a take-off angle that is less than $45^{\circ}$.

In his long jump simulation study, Alexander (1990) reported a take-off angle of $22^{\circ}$ for a jump from a run-up speed of $10.0 \mathrm{~m} \cdot \mathrm{s}^{-1}$. This value is in good agreement with the experimental data (Figure. 3), but Alexander did not comment on the relation between take-off angle and run-up speed. Seyfarth et al. (2000) reported the relation between take-off angle and run-up speed, but their model systematically underestimates the optimum take-off angle by several degrees (Figure 3). The authors argue that the simulation take-off angles are lower than for actual jumps because the model does not include the distributed masses of the take-off leg, and so does not accurately reproduce the large initial peak in the ground reaction force.

\section{Leg angle at touchdown}

The relation between the optimum leg angle at touchdown and run-up speed is shown in Figure 4. The gradient of the line of best fit to the data is $-0.6 \pm 0.2$ degrees per $\mathrm{m} \cdot \mathrm{s}^{-1}$, indicating that the optimum leg angle at touchdown decreased slightly with increasing run-up speed. This relation arises because a faster run-up speed requires the athlete to increase the duration of the foot contact in order to generate a high vertical take-off speed. The athlete therefore plants the foot farther ahead of the centre of mass at touchdown, and hence has a lower leg angle. The models of Alexander (1990) and Seyfarth et al. (2000) overestimate the optimum leg angle at touchdown by several degrees.

\section{Knee angle at touchdown}

The athlete in this study steadily increased his knee angle at touchdown with increasing run-up speed (Figure 5). A straighter knee may be required at high run-up speeds to prevent excessive flexion of the knee during the take-off. Lees et al. (1993) suggest that the greater the knee is flexed at touchdown, the more likely it is to continue to flex during the take-off and the more energy is dissipated by the leg muscles in eccentric contraction. A straighter take-off leg probably has a smaller moment arm about the knee for the ground reaction force, and is therefore more resistant to flexion. A straighter leg during the take-off allows the centre of mass to pivot up over the take-off foot, and hence generate a greater vertical speed and a longer jump distance.

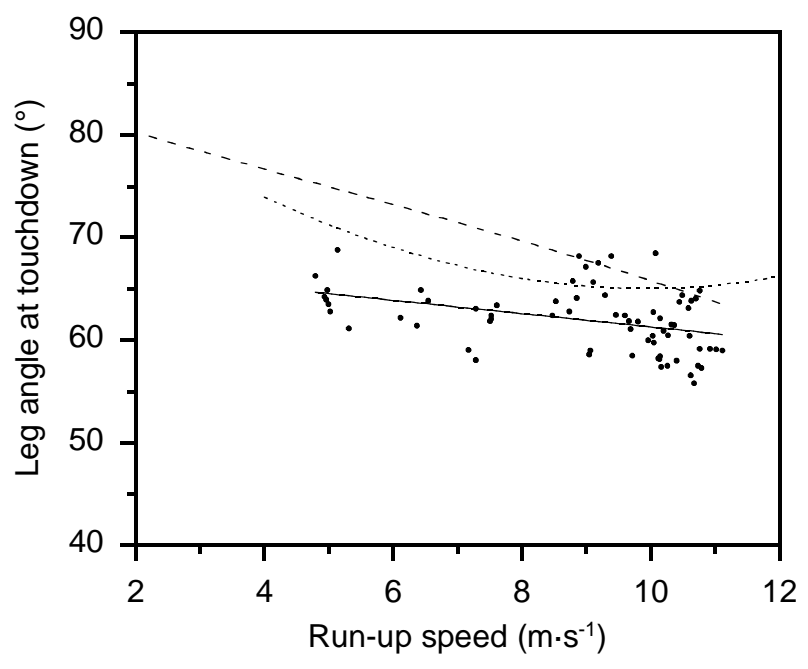

Figure 4. Slight decrease in touchdown leg angle with run-up speed. Also shown is the line of best fit to the data (solid line), and the simulation results from the mathematical models of Alexander (long-dashed line) and Seyfarth et al. (short-dashed line).

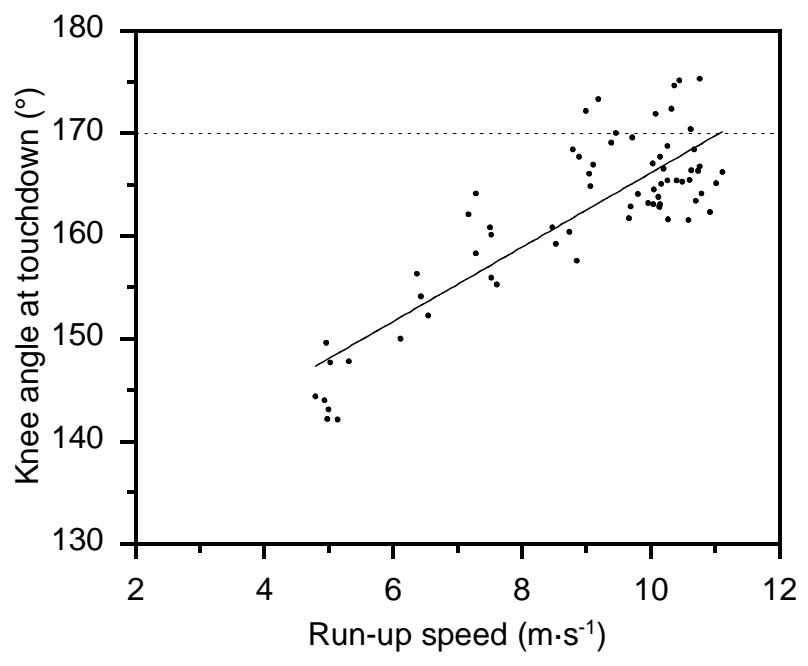

Figure 5. Increase in touchdown knee angle with run-up speed. Also shown is the line of best fit to the data (solid line). The simulations by Alexander and Seyfarth et al. assumed a constant knee angle of $170^{\circ}$ (short-dashed line).

Both Alexander (1990) and Seyfarth et al. (2000) used a constant knee angle of $170^{\circ}$ in their jump simulations. However, additional simulations by Seyfarth et al. suggest that a straighter knee is always beneficial. They reported that a larger knee angle leads to a longer jump distance, a higher take-off angle, and a reduction in the fraction of mechanical energy that is lost during the take-off. Over the range of knee angles investigated $\left(150-170^{\circ}\right)$, the changes were approximately linear with changes in knee angle.

The angle of the knee at touchdown was measured in cross-sectional studies of the long jump. In a study of the 12 long jump finalists at the 1997 World Championships in Athletics, Arampatzis et al. (1999) reported that the men used a straighter knee angle at touchdown (mean $=166^{\circ}$ ) than the women $\left(\right.$ mean $\left.=161^{\circ}\right)$. The present study suggests 
that the optimum knee angle increases at a rate of about 3.6 $\pm 0.3^{\circ}$ per $1.0 \mathrm{~m} \cdot \mathrm{s}^{-1}$ increase in run-up speed, and so about $80 \%$ of the observed difference in the study by Arampatzis et al. is accounted for by the differences in average run-up speed between the men (mean $=10.6 \mathrm{~m} \cdot \mathrm{s}^{-1}$ ) and women $\left(\right.$ mean $\left.=9.5 \mathrm{~m} \cdot \mathrm{s}^{-1}\right)$. The remainder is probably due to a difference in knee extensor strength between men and women, with the stronger male athletes able to support a greater optimum knee angle at touchdown.

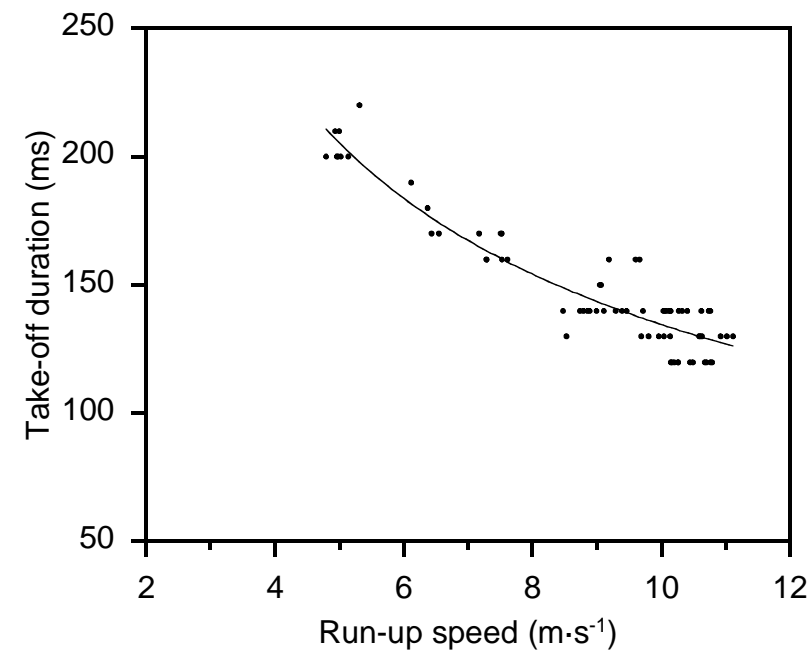

Figure 6. Decrease in take-off duration with run-up speed. Also shown is the line of best fit to the data (solid line). No simulation results are available for comparison.

\section{Take-off duration}

The take-off duration decreased with increasing run-up speed (Figure 6). A simplistic view of the long jump takeoff says that the take-off duration $(\Delta t)$ is determined by the ratio of the horizontal displacement $(\Delta d)$ and the average horizontal velocity $(v)$ of the centre of mass during the takeoff phase (i.e. $\Delta t=\Delta d / v$ ). Therefore, if an athlete uses a constant rotational range of motion of the take-off leg during the take-off, the take-off duration will vary in proportion to $v^{-1}$. However, for the athlete in this study the optimum range of motion of the take-off leg increased slightly with increasing run-up speed, and so the relation between take-off duration and run-up speed was not quite the simplistic $v^{-1}$ relation suggested above. As the run-up speed increased the athlete tended to use a lower leg angle at touchdown (Figure 4). Also, as the run-up speed increased the athlete had a lower take-off angle (Figure 3), and therefore the take-off leg made a greater angle at the instant of take-off. The net result was that the total rotational range of motion of the take-off leg increased from about $40^{\circ}$ at a run-up speed of $5 \mathrm{~m} \cdot \mathrm{s}^{-1}$, to about $60^{\circ}$ at a run-up speed of 11 $\mathrm{m} \cdot \mathrm{s}^{-1}$. The fitted curve in Figure 6 indicates that the take-off duration is proportional to $v^{-0.6}$.

Alexander (1990) and Seyfarth et al. (2000) did not report simulation results for the relation between take-off duration and run-up speed. However, both investigators noted that their predicted take-off duration for a typical jump was considerably shorter than for actual jumps.
Alexander reported a take-off duration of $65 \mathrm{~ms}$ for a jump from a run-up speed of $10.0 \mathrm{~m} \cdot \mathrm{s}^{-1}$, and Seyfarth et al. reported a take-off duration of $110 \mathrm{~ms}$ for a jump from a run-up speed of $9 \mathrm{~m} \cdot \mathrm{s}^{-1}$. Alexander presumed that the discrepancy between the model and observed values arises because the model does not have a foot segment and does not include the compliance of the take-off foot and shoe.

\section{Mechanical energy}

The change in the athlete's mechanical energy during the take-off was determined mainly by the change in the athlete's kinetic energy (i.e. speed), rather than by changes in potential energy (i.e. height). The athlete's potential energy increased during the take-off because the centre of mass at take-off was higher than at touchdown. However, the height difference between take-off and touchdown decreased only slightly with increasing run-up speed. Recall that the athlete lost speed between touchdown and take-off, and that the speed loss increased with increasing run-up speed (Figure 2). The overall result was that at speeds below about $8 \mathrm{~m} \cdot \mathrm{s}^{-1}$ the athlete had net gain in mechanical energy, and at higher speeds the athlete had a net loss (Figure 7). Alexander (1990) did not report results for the change in mechanical energy during the take-off. Seyfarth et al. (2000) reported the relation between take-off energy and run-up speed, but their model underestimates the rate of change in the percentage of touchdown energy that is transferred to the take-off (Figure 7).

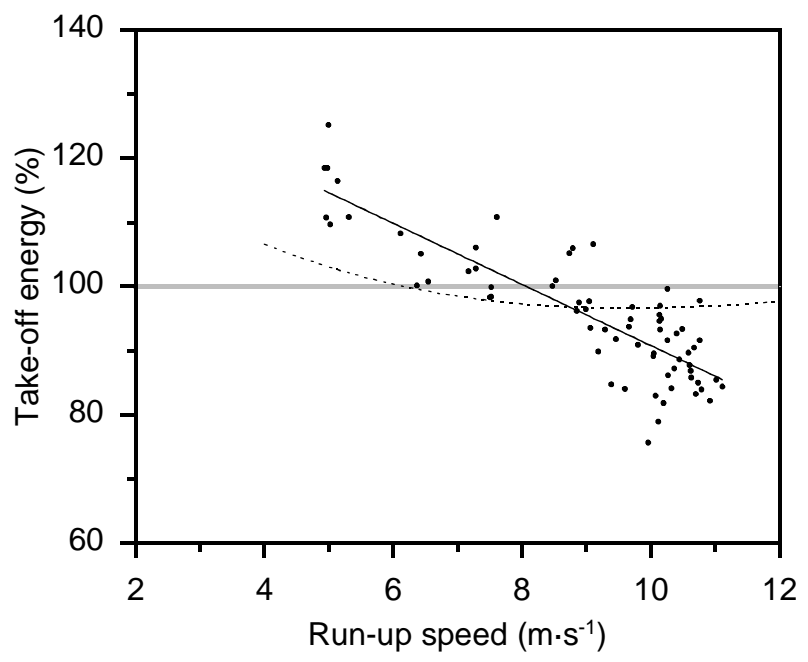

Figure 7. Decrease in take-off mechanical energy with run-up speed. Values are relative to the mechanical energy at touchdown. Also shown is the line of best fit to the data (solid line), the simulation result from the mathematical model of Seyfarth et al. (short-dashed line), and the line of $100 \%$ transfer of touchdown energy into take-off energy (grey line).

\section{Relations between jump distance and touchdown variables}

This study confirmed that performance in the long jump is determined mainly by the athlete's run-up speed (Hay et al., 1986; Hay \& Nohara, 1990; Lees et al., 1994). For the athlete studied here, the coefficient of determination for the 
fitted curve to the jump distance versus run-up speed data was $r^{2}=0.96$. That is, variations in run-up speed accounted for $96 \%$ of the observed variation in jump distance (Figure 1).

The large scatter in the data about the fitted curves in Figures 4 and 5 suggest that jump distance is insensitive to precise selection of the leg angle and knee angle at touchdown. To determine the relations between jump distance, leg angle, and knee angle, these variables were detrended with respect to run-up speed using the equations for the curves of best fit shown in Figures 1, 4 and 5. The standard deviation of the residuals was $22 \mathrm{~cm}$ for jump distance, $2.9^{\circ}$ for leg angle and $4.3^{\circ}$ for knee angle. Because jump distance increases at a rate of about 6-9 cm per 0.1 $\mathrm{m} \cdot \mathrm{s}^{-1}$ increase in run-up speed (Figure 1), about 9-13 $\mathrm{cm}$ of the residual variation in jump distance $(22 \mathrm{~cm})$ may be attributed to the uncertainty in the measurement of run-up speed $\left( \pm 0.15 \mathrm{~m} \cdot \mathrm{s}^{-1}\right)$. The residual jump distance showed only weak positive correlations with leg angle ( $r=0.15, P=$ $0.32)$ and with knee angle $(r=0.25, P=0.10)$. The residual jump distance increased at a rate of $1.1 \pm 1.1 \mathrm{~cm}$ per degree increase in leg angle, and $0.9 \pm 0.5 \mathrm{~cm}$ per degree increase in knee angle. Therefore, variations in leg angle and knee angle at touchdown accounted for $3 \pm 3 \mathrm{~cm}$ and $4 \pm 2 \mathrm{~cm}$ of the residual variation in jump distance. The remaining variation in jump distance may be due to variations in other technique variables, such as the toe-board distance at takeoff, the leg extensor forces generated by the athlete during the take-off, motion of the arms and free leg during the takeoff, and the landing technique.

Similar conclusions were reached using a nonlinear multiple regression analysis of the jump distance. A second-degree polynomial equation in run-up speed produced a large coefficient of determination $\left(r^{2}=0.96\right)$, and including the leg angle and knee angle in the regression equation only marginally increased its predictive capability. The simulation results of Alexander (1990) and Seyfarth et al. (2000) agree with the observation that jump distance is insensitive to precise selection of the touchdown leg angle. In their models an athlete jumps to within about $5 \mathrm{~cm}$ of the optimum jump distance (at any given run-up speed) if he uses a leg angle that is within $\pm 3^{\circ}$ of the optimum leg angle.

\section{Discussion}

Overall, the simulation results from the mathematical models Alexander (1990) and Seyfarth et al. (2000) are in reasonable agreement with the experimental data from the experienced male long jumper. Both Alexander and Seyfarth et al. found jump performance and take-off technique to be relatively insensitive to the properties of the muscle, which suggests that it is more important to have an accurate geometrical representation of the athlete. Alexander notes that the geometrical representation of the athlete in his model could be improved by including a foot segment. The maximum knee torque $\left(860 \mathrm{~N} \cdot \mathrm{m}^{-1}\right.$ for a $70 \mathrm{~kg}$ athlete) used in his jump simulations is larger than that expected for an athlete because the model does not have a foot segment and so places the ground reaction force at the distal end of the tibia, rather than on the ball of the foot.
This increases the perpendicular distance between the knee joint and the line of action of the ground reaction force, and consequently the model requires an unrealistically large knee torque to produce a realistic ground reaction force.

In the simulated jumps by Alexander (1990) and Seyfarth et al. (2000) the knee angle at touchdown was set at $170^{\circ}$. The present study showed that in actual jumps the knee angle at touchdown increases with increasing run-up speed. Therefore a model of the long jump take-off should include the knee angle at touchdown as one of the technique variables.

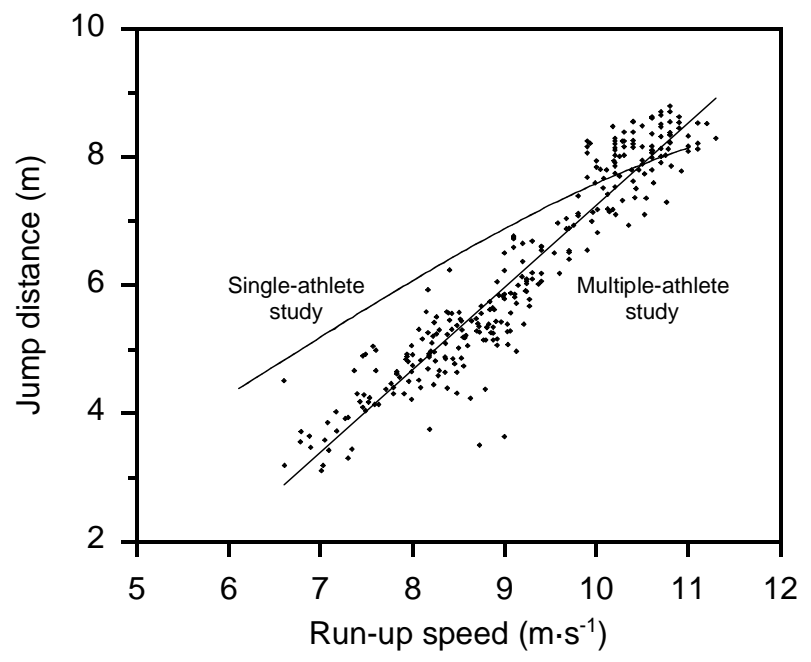

Figure 8. Comparison of results from the multiple-athlete (crosssectional) study of Hay (1993b) and the present single-athlete study. Data points for the single-athlete study are shown in Figure 1. The multiple-athlete data is courtesy of Jim Hay.

\section{Comparison to cross-sectional studies}

In this study, experimental data for the relations between run-up speed and take-off technique were obtained using direct intervention upon a single subject. A range of run-up speeds $\left(4.8-11.1 \mathrm{~m} \cdot \mathrm{s}^{-1}\right)$ was obtained that was much greater than if the study was restricted to competition jumps by the athlete. Figure 8 compares the observed relation between jump distance and run-up speed to data from Hay's crosssectional study of long jumpers (Hay, 1993b). Hay’s study examined the relation between jump distance and run-up speed for 306 jumps by 39 male and 28 female long jumpers. The study considered jumpers with a wide range of ability, from high school athletes through to elite athletes. The slope of the linear regression equation for the jump distance versus run-up speed data is 1.28 (i.e. jump distance increases at a rate of $12.8 \mathrm{~cm}$ per $0.1 \mathrm{~m} \cdot \mathrm{s}^{-1}$ increase in runup speed.). However, this should not be interpreted as indicating the expected improvement in jump distance with increasing run-up speed for an individual athlete. We suggest that the main cause of variations in ability among athletes is differences in dynamic muscular strength. The slope of the regression line from the cross-sectional study therefore indicates how the jump distance for a typical athlete will change in response to a change in muscular strength (Bridgett, Galloway, \& Linthorne, 2002). 
In conclusion, the take-off technique used by the male long jumper in this study changed in response to systematic changes in his run-up speed. As the athlete increased his run-up speed, the jump distance and take-off speed increased, the optimum leg angle at touchdown remained almost unchanged, and the optimum take-off angle and takeoff duration steadily decreased. To achieve the greatest jump distance this athlete should use a run-up speed that is as fast as possible and plant the take-off leg at about $61^{\circ}$ to the horizontal with a minimum of knee flexion. Although this study examined the influence of changes in run-up speed on the take-off technique of a single athlete, it is possible to generalise the results of the study. The mathematical models of Alexander (1990) and Seyfarth et al. (2000) have established that the relations between the technique variables that were observed in the present study arise from the mechanics of the system, and not from individual idiosyncracies of technique. Therefore, similar relations to the ones presented here may be expected for other experienced long jumpers.

\section{Acknowledgments}

This work was supported by the New South Wales Institute of Sport. Thanks to Keith Connor for arranging the participation of the athlete, and to Margy Galloway for assistance with the filming and biomechanical analysis. Thanks also to Jim Hay for supplying the data from his cross-sectional study of long jumpers.

\section{References}

Alexander, R.McN. (1990). Optimum techniques for high and long jumps. Philosophical Transactions of the Royal Society of London: Series B, 329, 3-10.

Arampatzis, A., Brüggemann, G.-P., \& Walsch, M. (1999). Long jump. In: Biomechanical Research Project Athens 1997 Final Report (edited by G.-P. Brüggemann, D. Koszewski \& H. Müller), pp. 82-113. Oxford: Meyer \& Meyer Sport.

Avela, J., Kryolainen, H., \& Komi, P.V. (1988). Changes in mechanical energy transfer and moment analysis during long jump take-off. Scandinavian Journal of Sports Sciences, 10, 1-5.

Bridgett, L.A., Galloway, M., \& Linthorne, N.P. (2002). The effect of run-up speed on long jump performance. In Scientific Proceedings of the XXth International Symposium on Biomechanics in Sports, Cáceras, Spain, July 1-5, 2002. (edited by K.E. Gianikellis), pp. 80-83. Cáceras: Universidad de Extremadura.

Challis, J. (1997). Estimation and propagation of experimental errors. In: Biomechanical Analysis of Movement in Sport and Exercise. (edited by R. Bartlett), pp. 105-124. Headingley, Leeds: British Association of Sport and Exercise Sciences.

Dapena, J., McDonald, J., \& Cappaert, J. (1990). A regression analysis of high jumping technique. International Journal of Sport Biomechanics, 6, 246261.
Dempster, W.T. (1955). Space Requirements of the Seated Operator. (WADC-TR-55-159) Wright-Patterson Air Force Base, $\mathrm{OH}$.

Greig, M.P., \& Yeadon, M.R. (2000). The influence of touchdown parameters on the performance of a high jumper. Journal of Applied Biomechanics, 16, 368-380.

Hay, J.G. (1993a). The Biomechanics of Sports Techniques, $4^{\text {th }}$ edn. Englewood Cliffs, NJ: Prentice-Hall.

Hay, J.G. (1993b). Citius, altius, longius (faster, higher, longer): the biomechanics of jumping for distance. Journal of Biomechanics, 26(Suppl. 1), 7-21.

Hay, J.G., \& Nohara, H. (1990) Techniques used by elite long jumpers in preparation for takeoff. Journal of Biomechanics, 23, 229-239.

Hay, J.G., Miller, J.A., \& Cantera, R.W. (1986). The techniques of elite male long jumpers. Journal of Biomechanics, 19, 855-866.

Hay, J.G., Thurson, E.M., \& Kippenham, B.C. (1999). Changes in muscle-tendon length during the take-off of a running long jump. Journal of Sports Sciences, 17, 159-172.

Hill, A.V. (1938). The heat of shortening and the dynamic constants of muscle. Proceedings of the Royal Society of London. Series B, Biological Sciences, 126, 136-195.

Herzog, W. (1986). Maintenance of body orientation in the flight phase of long jumping. Medicine and Science in Sports and Exercise, 18, 231-241.

IAAF. (2004). IAAF Handbook 2004-2005. Monaco: International Association of Athletic Federations.

Lees, A., Fowler, N., \& Derby, D. (1993). A biomechanical analysis of the last stride, touch-down, and take-off characteristics of the women's long jump. Journal of Sports Sciences, 11, 303-314.

Lees, A., Graham-Smith, P., \& Fowler, N. (1994). A biomechanical analysis of the last stride, touchdown, and takeoff characteristics of the men's long jump. Journal of Applied Biomechanics, 10, 61-78.

Lees, A., Rojas, J., Cepero, M., Soto, V., \& Gutierrez, M. (2000). How the free limbs are used by elite high jumpers in generating vertical velocity. Ergonomics, 43, 1622-1636.

Linthorne, N.P., Guzman, M.S., \& Bridgett, L.A. (2005). Optimum take-off angle in the long jump. Journal of Sports Sciences, 23, 703-712.

Nixdorf, E., \& Brüggemann, P. (1988). Biomechanical analysis of the long jump. In Scientific Report on the Second IAAF World Championships in Athletics, 2nd edn. pp. E1-E54. Monaco: International Athletic Foundation.

Nixdorf, E., \& Brüggemann, G-P. (1990). Biomechanical analysis of the long jump. In Scientific Research Project at the Games of the XXIVth Olympiad - Seoul 1988 Final Report. (edited by G.-P. Brüggemann \& B. Glad), pp. 263-301. Monaco: International Athletic Foundation.

Seyfarth, A., Blickhan, R., \& Van Leeuwen, J.L. (2000). Optimum take-off techniques and muscle design for long jump. The Journal of Experimental Biology, 203, 741750.

Siluyanov, V., \& Maximov, R. (1977). Speed and strength in the long jump (in Russian). Legkaya Athletika, 10, 18. 
Translated by Michael Yessis and reported in Yessis Review of Soviet Physical Education and Sports, 13, 7173 (1978).

Winter, D.A. (1990). Biomechanics and Motor Control of Human Movement, 2nd edn. New York: John Wiley.

$\mathrm{Yu}$, B. (1999). Horizontal-to-vertical velocity conversion in the triple jump. Journal of Sports Sciences, 17, 221229. 